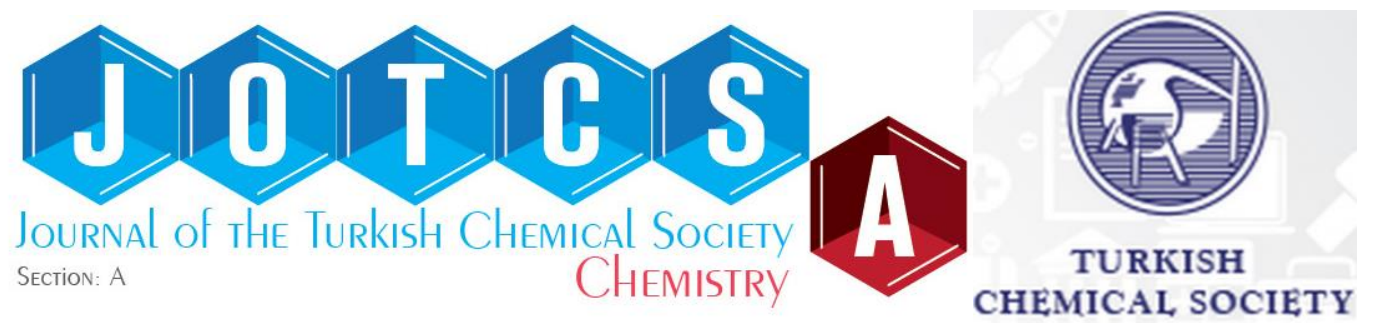

\title{
Isochamaejasmin and other Flavonoids Isolated from an Endemic Algerian Desert Species
}

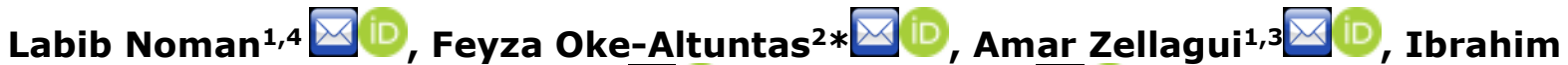 \\ Demirtas $^{4}$ (D), Rhouati Salah 1 .
}

${ }^{1}$ University of Mentouri Brothers-Constantine I, Faculty of Science, Department of Chemistry, Constantine, Algeria

${ }^{2}$ Gazi University, Faculty of Science, Department of Biology, Ankara, Turkey

${ }^{3}$ University of Larbi Ben Mhidi Oum El Bouaghi, Department of Life Science and Nature, Oum El Bouaghi, Algeria

${ }^{4}$ Cankiri Karatekin University, Faculty of Science, Department of Chemistry, Cankiri, Turkey

Abstract: Thymelaea microphylla Coss. et Dur is an endemic desert species from Algeria belonging to Thymelaeaceae family. The dichloromethane-methanolic extract from aerial parts of $T$. microphylla was subjected to a silica gel column. Three flavonoids were isolated from the extract; isochamaejasmin (1), cis-tiliroside (2) and trans-tiliroside (3). The structures of the compounds were determined on the basis of the HPLC-TOF/MS, 1D and 2D NMR spectroscopic analysis. To the best of our knowledge, compound (1) was isolated from $T$. microphylla for the first time and there is no report in the literature. Moreover, in this study, antioxidant activity of the compound (3) was also evaluated.

Keywords: Thymelaea microphylla, flavonoids, antioxidant.

Submitted: November 13, 2017. Accepted: February 05, 2018.

Cite this: Noman L, Oke-Altuntas F, Zellagui A, Demirtas I, Salah R. Isochamaejasmin and other Flavonoids Isolated from an Endemic Algerian Desert Species. JOTCSA. 2018;5(2):347-54.

DOI: http://dx.doi.org/10.18596/jotcsa.351651.

*Corresponding author. E-mail: feyzaoke@gazi.edu.tr. 


\section{INTRODUCTION}

Thymelaeaceae family consists of approximately 67 genera and 1200 species. It is widespread in the tropics and temperate climate of the Earth, particularly in Africa (1). Although this family is a small taxon, it has very varied uses, giving them a significant economic importance in the regions where they grow $(2,3)$. Thymelaea is one of the genus of this family, which contains about 30 species in the world (4). Some species of this genus have been used in the traditional medicine and reported have some biological activities such as antidiabetic, antihypertensive (5), anti-inflammatory (6) as well as antimicrobial and antioxidant activity (7).

Thymelaea microphylla called "Al Methnan" is a small shrub and its length does not exceed a meter. It has been used in folk medicine for the treatment of wounds, erysipelas, skin cancer, pimples, and abscess (8). Several studies have shown that this species had remarkable antibacterial, antioxidant (9, 10), antiinflammatory (6), and antiproliferative (11) activities. Phytochemical studies on this species were indicated the presence of bicoumarin and their glycoside derivatives, linear-type furanocoumarin glucosides and simple coumarin glucosides (12). Daphnoretine (bicoumarin), umbelliferone (simple coumarin) and prestegane B (lignans) have been isolated from the aerial parts of Thymelaea microphylla (11). The report related to the chemical analysis of Thymelaea microphylla essential oil in the literature showed the major components were D-menthone (41.86\%), 2-undecanone (23.74\%), pulegone (11.94\%) and perillal $(9.34 \%)(13)$.

Recently, we have reported the new benzimidazole and six known compounds with their antiproliferative and antioxidant activities from $T$. microphylla (11). We herein report the isolation and structural elucidation of three flavonoids from the chloromethanolic extract of $T$. microphylla. Also, in this study, we investigated the antioxidant activity of the compound (3).

\section{EXPERIMENTAL SECTION}

\section{Extraction and isolation}

Dried aerial parts of Thymelaea microphylla $(2200 \mathrm{~g})$ were crushed and extracted with $\mathrm{CH}_{2} \mathrm{Cl}_{2}$ : $\mathrm{MeOH}(1: 1, \mathrm{v}: \mathrm{v})$ at room temperature. The extract was concentrated in vacuo to obtain the crude extract $(F ; 103.7 \mathrm{~g})$, which was fractionated by column chromatography eluted with $\mathrm{n}$ hexane, followed by a gradient of $n$-hexane and $\mathrm{CH}_{2} \mathrm{Cl}_{2}$ up to $100 \% \mathrm{CH}_{2} \mathrm{Cl}_{2}$ and $\mathrm{CH}_{2} \mathrm{Cl}_{2}-\mathrm{MeOH}$ up to $100 \% \mathrm{MeOH}$ to obtain 9 fractions. The fraction 6 ( F6; $5.5 \mathrm{~g})$ was subjected to flash column chromatography eluted with $\mathrm{n}$-hexane, followed by a gradient of $\mathrm{n}$-hexane- $\mathrm{CH}_{2} \mathrm{Cl}_{2}$ up to $100 \%$ $\mathrm{CH}_{2} \mathrm{Cl}_{2}$ and $\mathrm{CH}_{2} \mathrm{Cl}_{2}$-EtOAc up to $100 \%$ EtOAc and EtOAc-ethanol up to $100 \%$ ethanol to obtain 25 fractions from collective tubes and 51 fractions from waste tubes. The fraction F6-C4 from collective tubes was purified by TLC eluted with n-hexane: $\mathrm{CH}_{2} \mathrm{Cl}_{2}: \mathrm{MeOH}(1: 2: 0.5, \mathrm{v}: \mathrm{v}: \mathrm{v}$ ) to 
afford compound 1 (isochamaejasmin; $11.35 \mathrm{mg}$ ). The fraction 7 (F7; $6.3 \mathrm{~g}$ ) was applied on column chromatography eluted with n-hexane: $\mathrm{CH}_{2} \mathrm{Cl}_{2}$ : $\mathrm{MeOH}(0,5: 2: 1)$ to obtain 12 subfractions, the precipitate from sub-fraction 7 purified by TLC eluted with the same system to afford compounds (2) (cis-tiliroside; $5.14 \mathrm{mg}$ ) and (3) (trans-tiliroside; $6.43 \mathrm{mg}$ ).

\section{General experimental procedure}

${ }^{1} \mathrm{H}(400 \mathrm{MHz})$ and ${ }^{13} \mathrm{C}$ NMR $(100 \mathrm{MHz})$ spectra were recorded on Bruker Avence III spectrometer (in DMSO- $\mathrm{d}_{6}$ with tetramethylsilane (TMS) as internal standard). HPLC-TOF/MS spectra were recorded in the negative ion mode on an Agilent 6210 spectrometer. Column chromatography and thin-layer chromatography were performed over silica gel (Merck, Germany), 60A and $60 F_{254}$, respectively.

\section{Antioxidant activity}

Radical scavenging activity of the compound (3) was determined according to the method of Blois (14). BHT was used as a positive control. Scavenging of DPPH radical was calculated according to the formula: Radical scavenging $\%=[($ Acontrol - Asample $) / A$ control $] \times 100$.

Metal chelating activity of the compound (3) was determined according to the method of Decker and Welch (15), with some modifications. EDTA was used as a positive control.

\section{RESULTS AND DISCUSSION}

Compound (1) was obtained as an amorphous powder. The mass experiment was carried out using HPLC-TOF/MS in a negative mode, which presented an ion whose quasi-molecular at $\mathrm{m} / \mathrm{z}$ 541 corresponding to the molecular formula $\mathrm{C}_{30} \mathrm{H}_{22} \mathrm{O}_{10}$. The ${ }^{1} \mathrm{H}$ NMR spectrum of 1 showed pair signals of doublets at $\delta 5.8$ and 5.7 (each $2 \mathrm{H}, \mathrm{J}=2.0 \mathrm{~Hz}$ ) were assigned to 6, 6", and 8, 8" protons, respectively. Four signals of ortho-coupled doublets $(\mathrm{J}=8.5 \mathrm{~Hz})$ at $\delta 7.0,6.9,6.8$ and 6.7 integrating for two protons each, were assigned to $\left(6^{\prime}, 6^{\prime \prime \prime}\right),\left(2^{\prime}, 2^{\prime \prime \prime}\right),\left(5^{\prime}, 5^{\prime \prime \prime}\right)$ and $\left(3^{\prime}, 3^{\prime \prime \prime}\right)$ protons, respectively, along with two signals of doublets with coupling constant $(\mathrm{J}=12.0 \mathrm{~Hz})$ at $\delta 5.71$ and 2.7 for two protons each, assigned to 2, 2" and 3, 3" protons, respectively, characteristic for the biflavanone structure. ${ }^{13} \mathrm{C}$ NMR spectral data of 1 (see Table I), displayed that C-3 was linked with C-3" according to the resonance of C-3 and C-3" (49.3 ppm), and compared with carbon resonance of naringenin $(43.7 \mathrm{ppm})(16)$. The stereochemistry at the C2/C-3 and C-2"/C-3" positions were determined as trans-trans geometry based on the values of the coupling constants $(\mathrm{J}=12.0 \mathrm{~Hz})$ of the protons $\left(\mathrm{H}-2 / \mathrm{H}-3\right.$ and $\left.\mathrm{H}-2^{\prime \prime} / \mathrm{H}-3^{\prime \prime}\right)$, All these NMR data together with the mass spectrum suggested the structure of compound 1 was elucidated as isochamaejasmin (17). Compound 2 was obtained as a yellow powder and had a molecular formula $\mathrm{C}_{30} \mathrm{H}_{26} \mathrm{O}_{13}$ established by HPLC-TOF/MS (m/z $\left.593[\mathrm{M}-\mathrm{H}]^{-}\right)$. Compound 3 was obtained as a yellow powder, the molecular formula of which was determined to be $\mathrm{C}_{30} \mathrm{H}_{26} \mathrm{O}_{13}$ from the 


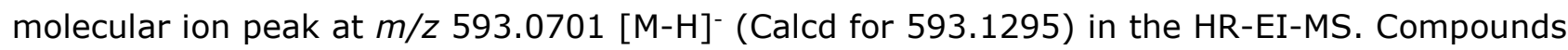
2 and 3 were identified as cis-tiliroside and trans-tiliroside, respectively, by comparing their EIMS, ${ }^{1} \mathrm{H}$ NMR and spectra with published data ${ }^{13} \mathrm{C}$ NMR $(18,19)$ (Table 1, Table 2, Figure 1.).

Table 1: ${ }^{13} \mathrm{C}$ NMR spectral data of compounds (Cmp) (1), (2), and (3).

\begin{tabular}{|c|c|c|c|c|c|}
\hline Position & Cmp (1) & Position & Cmp (2) & Position & Cmp (3) \\
\hline $2 / 2^{\prime \prime}$ & 83.4 & 2 & 157.4 & 2 & 156.5 \\
\hline $3 / 3^{\prime \prime}$ & 49.3 & 3 & 133 & 3 & 132.4 \\
\hline $4 / 4^{\prime \prime}$ & 195.5 & 4 & 177.3 & 4 & 177 \\
\hline 10/10" & 101.2 & 10 & 113.2 & 10 & 113 \\
\hline $5 / 5^{\prime \prime}$ & 164 & 5 & 160. 2 & 5 & 159.4 \\
\hline $6 / 6^{\prime \prime}$ & 97 & 6 & 100.6 & 6 & 99.3 \\
\hline $7 / 7^{\prime \prime}$ & 170 & 7 & 159.3 & 7 & 158.3 \\
\hline $8 / 8^{\prime \prime}$ & 96 & 8 & 95 & 8 & 94.2 \\
\hline $9 / 9^{\prime \prime}$ & 162.7 & 9 & 161.2 & 9 & 160.2 \\
\hline $1^{\prime} / 1^{\prime \prime \prime}$ & 127 & $1^{\prime}$ & 121.4 & $1^{\prime}$ & 121 \\
\hline $2^{\prime} / 2^{\prime \prime \prime}$ & 131.4 & $2^{\prime} / 6^{\prime}$ & 131 & $2^{\prime} / 6^{\prime}$ & 130 \\
\hline $3^{\prime} / 3^{\prime \prime \prime}$ & 116 & $3^{\prime} / 5^{\prime}$ & 115.5 & $3^{\prime} / 5^{\prime}$ & 114.3 \\
\hline $4^{\prime} / 4^{\prime \prime \prime}$ & 158 & $4^{\prime}$ & 160.1 & $4^{\prime}$ & 160 \\
\hline $5^{\prime} / 5^{\prime \prime \prime}$ & 116 & $1^{\prime \prime}$ & 103.3 & $1^{\prime \prime}$ & 102.5 \\
\hline \multirow[t]{12}{*}{$6^{\prime} / 6^{\prime \prime \prime}$} & 130 & $2^{\prime \prime}$ & 74.4 & $2^{\prime \prime}$ & 74.4 \\
\hline & & $3^{\prime \prime}$ & 73.34 & $3^{\prime \prime}$ & 72.4 \\
\hline & & $4 "$ & 70.24 & $4^{\prime \prime}$ & 69.42 \\
\hline & & $5^{\prime \prime}$ & 74.3 & $5^{\prime \prime}$ & 73.18 \\
\hline & & $6^{\prime \prime}$ & 63 & $6 "$ & 62.13 \\
\hline & & $1^{\prime \prime \prime}$ & 126 & $1^{\prime \prime \prime}$ & 124.2 \\
\hline & & $2^{\prime \prime \prime} / 6^{\prime \prime \prime}$ & 130 & $2^{\prime \prime \prime} / 6^{\prime \prime \prime}$ & 129 \\
\hline & & $3^{\prime \prime \prime} / 5^{\prime \prime \prime}$ & 116 & $3^{\prime \prime \prime} / 5^{\prime \prime \prime}$ & 114.3 \\
\hline & & $4^{\prime \prime \prime}$ & 160 & $4^{\prime \prime \prime}$ & 159.2 \\
\hline & & $7^{\prime \prime \prime}$ & 145.2 & $7^{\prime \prime \prime}$ & 144.5 \\
\hline & & $8^{\prime \prime \prime}$ & 114.5 & $8^{\prime \prime \prime}$ & 114 \\
\hline & & $9^{\prime \prime \prime}$ & 167.4 & $9^{\prime \prime \prime}$ & 166.4 \\
\hline
\end{tabular}

Table 2: ${ }^{1} \mathrm{HNMR}$ spectral data of compounds (Cmp) (1), (2), and (3).

\begin{tabular}{|c|c|c|c|c|c|}
\hline Position & Compound 1 & Position & Compound 2 & Position & Compound 3 \\
\hline $6 / 6 "$ & $5.78(d, J=2.01)$ & 6 & $6.0(d, J=2.2)$ & 6 & $6.2(d, J=2.3)$ \\
\hline $8 / 8^{\prime}$ & $5.70(d, J=2.01)$ & 8 & $6.2(d, J=2.2)$ & 8 & $6.3(d, J=2.3)$ \\
\hline $2^{\prime} / 2^{\prime \prime \prime}$ & $6.86(d, J=8.53)$ & $2^{\prime} / 6^{\prime}$ & $8.0(d, J=9.0)$ & $2^{\prime} / 6^{\prime}$ & $8.0(d, J=9.0)$ \\
\hline 6'/6"' & $6.98(d, J=8.53)$ & $3^{\prime} / 5^{\prime}$ & $6.8(d, J=8.8)$ & $3^{\prime} / 5^{\prime}$ & $6.9(d, J=8.8)$ \\
\hline $3^{\prime} / 3^{\prime \prime \prime}$ & $6.73(d, J=8.53)$ & $1^{\prime \prime}$ & $5.15(d, J=7.28)$ & $1^{\prime \prime}$ & $5.2(d, J=7.3)$ \\
\hline $5 ' / 5^{\prime \prime \prime}$ & $6.78(d, J=8.53)$ & $2^{\prime \prime}$ & $3.37(m)$ & $2^{\prime \prime}$ & $3.4(m)$ \\
\hline $2 / 2^{\prime \prime}$ & $5.71(d, J=12.30)$ & $3 "$ & $3.5(m)$ & $3 "$ & $3.5(m)$ \\
\hline \multirow[t]{8}{*}{$3 / 3^{\prime \prime}$} & $2.69(d, J=12.30)$ & $4^{\prime \prime}$ & $3.4(m)$ & $4^{\prime \prime}$ & $3.3(m)$ \\
\hline & & $5 "$ & $3.4(m)$ & $5 "$ & $3.47(m)$ \\
\hline & & 6"a & $4.32(d d, J=11.8-6.5)$ & 6"a & $4.3(d d, J=11.9-6.5)$ \\
\hline & & $6 " b$ & $4.18(d d, J=11.8-2.0)$ & $6 " b$ & $4.2(d d, J=11.9-2.0)$ \\
\hline & & $2^{\prime \prime \prime} / 6^{\prime \prime \prime}$ & $7.3(d, J=8.8)$ & $2^{\prime \prime \prime} / 6^{\prime \prime \prime}$ & $7.4(d, J=8.9)$ \\
\hline & & $3^{\prime \prime \prime} / 5^{\prime \prime \prime}$ & $6.8(d, J=9.0)$ & $3^{\prime \prime \prime} / 5^{\prime \prime \prime}$ & $6.8(d, J=9.3)$ \\
\hline & & $7^{\prime \prime \prime}$ & $7.4(d, J=12.3)$ & $7^{\prime \prime \prime}$ & $7.5(d, J=15.8)$ \\
\hline & & $8^{\prime \prime \prime}$ & $6.16(d, J=12.3)$ & $8^{\prime \prime \prime}$ & $6.18 d, J=15.8)$ \\
\hline
\end{tabular}


<smiles>O=C1c2c(O)cc(O)cc2O[C@H](c2ccc(O)cc2)[C@H]1[C@H]1C(=O)c2c(O)cc(O)cc2O[C@H]1c1ccc(O)cc1</smiles>

(1)

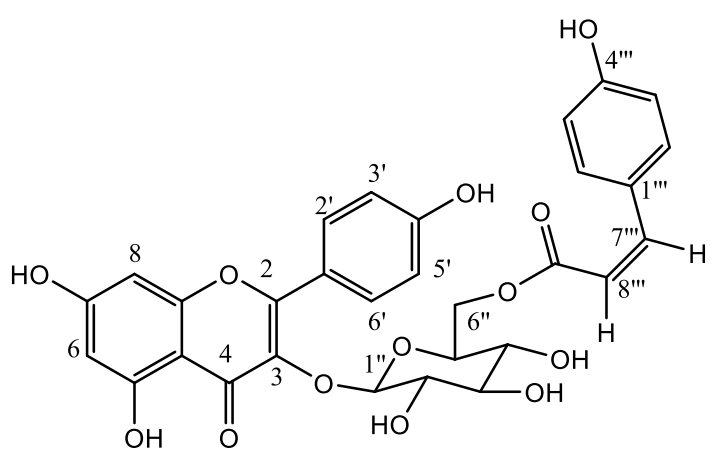

(2)

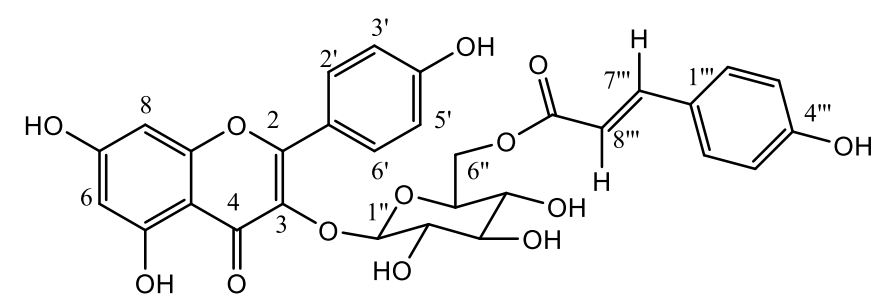

(3)

Figure 1: The structure of compounds 1, 2, and $\mathbf{3}$.

Trans-tiliroside compound (3) isolated from T. microphylla was studied in vitro for its metal chelating and scavenger properties. As can be seen Table 3, this compound ( $\mathrm{IC}_{50}=0.726 \pm$ $0.043 \mathrm{mg} / \mathrm{mL}$ ) exhibited lower DPPH scavenging effect than BHT (IC $50=0.023 \pm 0.001 \mathrm{mg} / \mathrm{mL}$ ) (Figure 2). On the other hand, compound (3) was not an active metal chelator at the concentration of $1 \mathrm{mg} / \mathrm{mL}$. According to the literature, several researchers reported that tiliroside compound has antioxidant activity (20-23). Sala, Recio (21) determined that the tiliroside has a high antioxidant activity measured by the DPPH test and reported the $\mathrm{IC}_{50}$ value of the this compound was about $6 \mu \mathrm{M}$, in the same range as that of the flavonol quercetin-3-0-glucoside. Ding (23) studied DPPH radical scavenging activity of the tiliroside compound which isolated from the fruits of Rubus chingii and reported as $13.7 \mu \mathrm{M}$. On the other hand, Mekhelfi (24) reported that the radical scavenging effect of trans-tiliroside compound isolated from $T$. microphylla (\% 21.82 at $10 \mathrm{mg} / \mathrm{mL}$ ). Li, Tian (22) presented that Astragalin (kaempferol-3-O$\beta$-D-glucopyranoside) and tiliroside (kaempferol-3-O- $\beta$-D-(6'-O-p-coumaroyl)glucopyranoside) both efficiently scavenged DPPH radicals; however, tiliroside showed higher DPPH radical scavenging ability than astragalin. They explained the reason of this situation as follows; $p$-coumaroyl moiety in tiliroside enhanced the efficiency of the hydrogen atom transfer-based pathways. 
Table 3: Antioxidant of compound 3 (trans-tiliroside)*.

\begin{tabular}{lll}
\hline \hline & $\begin{array}{l}\text { DPPH } \\
\text { IC }_{\mathbf{5 0}}(\mathbf{m g} / \mathbf{m L})\end{array}$ & $\begin{array}{l}\text { Metal chelating } \\
(\%, \text { at } \mathbf{1} \mathbf{~ m g} / \mathbf{m L})\end{array}$ \\
\hline Compound (3) & $0.726 \pm 0.043^{\mathrm{a}}$ & NA \\
BHT & $0.023 \pm 0.001^{\mathrm{b}}$ & NS \\
EDTA & NS & $93.1 \pm 0.2$ \\
\hline
\end{tabular}

*Values represent averages \pm standard deviations for triplicate experiments. Values in the same column with different superscripts ( $a$ and $b$ ) are significantly $(p<0.01)$ different. NA: not active at tested concentration, NS: not studied.

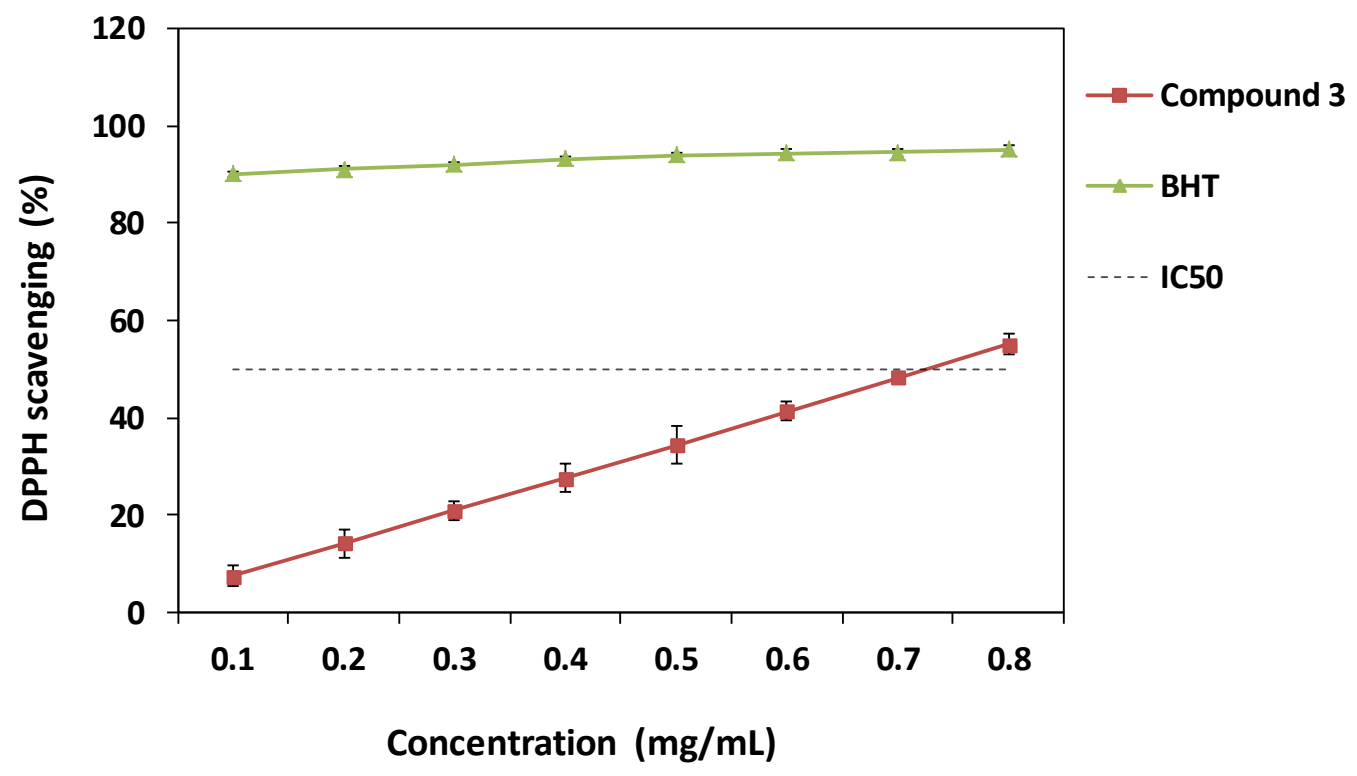

Figure 2: DPPH radical scavenging activity of compound (3).

\section{CONCLUSION}

In this study, three flavonoids; isochamaejasmin, cis-tiliroside, and trans-tiliroside were isolated from Thymelaea microphylla. The structures of the compounds were determined on the basis of the HPLC-TOF/MS, 1D and 2D NMR spectroscopic analysis. This is the first report on the isolation and structure elucidation of isochamaejasmin compound from this plant. Also, in this study, trans-tiliroside compound isolated from T. microphylla was evaluated for its antioxidant activity and found as a potent radical scavenger. These results suggest that trans-tiliroside compound may be used as a natural antioxidant in cosmetic, food, and pharmaceutical industries.

\section{ACKNOWLEDGMENT}

The authors are grateful for the partial financial support of the Ministère de l'Enseignement Supérieur et de la Recherche Scientifique (MESRES - Alger, Algeria); Turkish State Planning Organization [grant number DPT2010K120720]; and Cankiri Karatekin University. 


\section{REFERENCES}

1. Borris RP, Blaskó G, Cordell GA. Ethnopharmacologic and phytochemical studies of the Thymelaeaceae. Journal of Ethnopharmacology. 1988;24(1):41-91.

2. Takeuchi W, Golman M. The identity of eaglewood (Gyrinops, Thymelaeaceae), a new economic resource for Papua New Guinea. SIDA, Contributions to Botany. 2002;20(1):261-7.

3. Bredenkamp CL, van Wyk AE. Taxonomy of the genus Passerina (Thymelaeaceae). Bothalia: African Biodiversity \& Conservation. 2003;33:53-7.

4. Vincent MA, Thieret JW. Thymelaea passerina (Thymelaeaceae) in Ohio. SIDA, Contributions to Botany. 1987;12(1):75-8.

5. Bnouham M, Benalla W, Bellahcen S, Hakkou Z, Ziyyat A, Mekhfi H, et al. Antidiabetic and antihypertensive effect of a polyphenol-rich fraction of Thymelaea hirsuta L. in a model of neonatal streptozotocin-diabetic and NG-nitro-I-arginine methyl ester-hypertensive rats. Journal of Diabetes. 2012;4(3):307-13.

6. Dehimi K, Speciale A, Saija A, Dahamna S, Raciti R, Cimino F, et al. Antioxidant and antiinflammatory properties of Algerian Thymelaea microphylla Coss. and Dur. extracts. Pharmacognosy Magazine. 2016;12(47):203-10.

7. Trigui M, Hsouna AB, Tounsi S, Jaoua S. Chemical composition and evaluation of antioxidant and antimicrobial activities of Tunisian Thymelaea hirsuta with special reference to its mode of action. Industrial Crops and Products. 2013;41:150-7.

8. Ghanem H, Haba H, Marcourt L, Benkhaled M, Wolfender JL. Microphynolides A and B, new spirogamma-lactone glycosides from Thymelaea microphylla. Natural Product Research. $2014 ; 28(20): 1732-8$.

9. Noman L, Zellagui A, Hallis Y, Yaglioglu AS, Demirtas I, Gherraf N, et al. Antioxidant and antimicrobial activities of an endemic desert species Thymelea microphylla Coss. et Dur. Der Pharmacia Lettre. 2015; 7(1):118-21.

10. Kerbab K, Mekhelfi T, Zaiter L, Benayache S, Benayache F, Picerno P, et al. Chemical composition and antioxidant activity of a polar extract of Thymelaea microphylla Coss. et Dur. Natural Product Research. $2015 ; 29(7): 671-5$.

11. Noman L, Oke-Altuntas F, Zellagui A, Sahin Yaglioglu A, Demirtas I, M Cardoso S, et al. A novel benzimidazole and other constituents with antiproliferative and antioxidant properties from Thymelaea microphylla Coss. et Dur. Natural Product Research. 2017;31:2032-41.

12. Rizk A, Hammouda F, Ismail S. Phytochemical investigation of Thymelea hirsuta. 3. Coumarins. Acta Chimica Academiae Scientarium Hungaricae. 1975;85(1):107-15.

13. Labib SN, Zellagui A, Mesbah K, Gherraf N, Lahouel Mand Rhouati S. Essential oil Composition of Thymelea microphylla Coss et Dur. Der Pharmacia Lettre. 2010;2(5):428-31.

14. Blois MS. Antioxidant determinations by the use of a stable free radical. Nature. 1958;181:1199200.

15. Decker EA, Welch B. Role of ferritin as a lipid oxidation catalyst in muscle food. Journal of Agricultural and Food Chemistry. 1990;38(3):674-7.

16. Agrawal PK. Flavonoid glycosides. Carbon-13 NMR of flavonoids. Amsterdam, Elsevier, 1989, pp. 102-103.

17. Niwa M, Otsuji S, Tatematsu H, Liu G-Q, Chen X-F, Hirata Y. Stereostructures of two biflavanones from Stellera chamaejasme L. Chemical and Pharmaceutical Bulletin. 1986;34(8):3249-51.

18. Trendafilova A, Todorova M, Gavrilova A, Vitkova A. Flavonoid glycosides from Bulgarian endemic Alchemilla achtarowii Pawl. Biochemical Systematics and Ecology. 2012;43:156-8. 
19. Liao C-R, Kuo Y-H, Ho Y-L, Wang C-Y, Yang C-S, Lin C-W, et al. Studies on cytotoxic constituents from the leaves of Elaeagnus oldhamii Maxim. in non-small cell lung cancer A549 cells. Molecules. $2014 ; 19(7): 9515-34$.

20. Qiao W, Zhao C, Qin N, Zhai HY, Duan HQ. Identification of trans-tiliroside as active principle with anti-hyperglycemic, anti-hyperlipidemic and antioxidant effects from Potentilla chinesis. Journal of Ethnopharmacology. 2011;135(2):515-21.

21. Sala A, Recio MC, Schinella GR, Máñez S, Giner RM, Cerdá-Nicolás M, et al. Assessment of the antiinflammatory activity and free radical scavenger activity of tiliroside. European Journal of Pharmacology. 2003;461(1):53-61.

22. Li X, Tian $Y$, Wang $T$, Lin $Q$, Feng $X$, Jiang $Q$, et al. Role of the $p$-Coumaroyl Moiety in the Antioxidant and Cytoprotective Effects of Flavonoid Glycosides: Comparison of Astragalin and Tiliroside. Molecules. $2017 ; 22(7): 1165$.

23. Ding H-Y. Extracts and constituents of Rubus chingii with 1, 1-diphenyl-2-picrylhydrazyl (DPPH) free radical scavenging activity. International journal of molecular sciences. $2011 ; 12(6): 3941-9$.

24. Mekhelfi T, Adouni K, Zaiter L, Guella G, Benayache S, Benayache F, Venskutonis PR. Antioxidant activity of extracts, cis and trans tilirosides, and other compounds from Thymelaea microphylla Coss. et Dur. Der Pharmacia Lettre. 2016;8:233-9. 